\title{
Integrated Dynamic Aquaculture and Wastewater Treatment Modelling for Recirculating Aquaculture Systems
}

\author{
Torsten E. I. Wik ${ }^{a}$, Björn T. Lindén ${ }^{b}$, Per I. Wramner ${ }^{c}$ \\ ${ }^{a}$ Department of Signals and Systems, Chalmers University of Technology, SE-412 \\ 96 Göteborg, Sweden \\ ${ }^{b}$ Greenfish AB, Kvarngatan 2, SE-311 83 Falkenberg, Sweden \\ ${ }^{c}$ Coastal Management Research Center, Södertörn University, SE-14189 \\ Huddinge, Sweden
}

\begin{abstract}
Recirculating aquaculture systems (RAS) in land based fish tanks, where the fish tank effluent is biologically treated and then recirculated back to the fish tanks, offers a possibility for large scale ecologically sustainable fish production. In order to fully exploit the advantages of RAS, however, the water exchange should be as small as possible. This implies strong demands on the water treatment, e.g. the maintenance of an efficient nitrification, denitrification and organic removal. Because of the RAS complexity, though, dynamic simulations are required to analyze and optimize a plant with respect to effluent water quality, production and robustness. Here, we present a framework for integrated dynamic aquaculture and wastewater treatment modelling. It provides means to analyze, predict and explain RAS performance. Using this framework we demonstrate how a new and improved RAS configurations is identified.
\end{abstract}

Key words: Aquaculture; biofilm; control; integrated model; moving bed; wastewater

\section{Introduction}

The global harvest of wild fish has stagnated around 90 million tons a year and is not expected to rise (FAO, 2007). At the same time there is a steady increase in demand for fish, which has lead to a tremendous growth in global aquaculture 'industry'. Because of the impact on the environment, it is of utmost importance that the environmental damage often related to traditional fish farming is avoided in this expansion. Recirculating aquaculture systems 
(RAS) in land-based fish tanks, where the fish tank effluent is biologically treated and the water is recycled back to the rearing tanks, may become a key solution for large-scale ecologically sustainable fish production. This will be especially relevant in areas where water supply and/or effects of nutritional loads on surrounding aquatic systems limit the present scope for aquaculture production (Piedrahita, 2003).

With nearly complete recirculation ( $<1 \%$ diurnal water exchange) land based RAS have several environmentally important properties:

- The release of eutrophicating nutrients and organic matter can be reduced to minute levels, provided there is an efficient water purification process within the system.

- Conditioned, sterilized or otherwise controlled water sources may be used, which reduces risks of introducing pathogens from the surrounding.

- Land based RAS eliminates the risk of escapes that may cause genetic and ecological contamination of wild stocks.

- Minute water exchange opens for sterilization and elimination of pathogens in effluents.

- In temperate regions conservation of heat generated from pumps, aeration, fish activity etc., enhanced by insulated buildings and heat exchangers, allows cultivation of fast growing herbivore and omnivore species at temperatures optimal for growth all-year round. For such species, in contrast to the carnivores dominating aquaculture in the northern hemisphere, no fish meal in the feed is required, thus reducing the need for wild catch.

- In an aquaculture integrated with agriculture, where e.g. cereals constitute the main feed component, and aquaculture sludge is used as fertilizer (see Figure 1), the content of heavy metals in both fish and sludge produced in RAS can be controlled. Potential biomagnification of other compounds, such as organochlorides present in fish fed on fish meal (Serrano et al., 2003), can then also be avoided.

Two main reasons for RAS not being more widespread already, are problems associated with revenue and system instability. Even though open loop aquaculture is fairly stable, i.e. limited changes in feed and disturbances cause limited changes of their behavior, RAS, being feedback systems, are not necessarily stable. The problem of instability, in this case uncontrollable fluctuations in concentrations, populations and performance, is a consequence of the dynamic properties of a system. A proper analysis therefore requires a stand-point in dynamic feedback systems (e.g. Control Theory). Bacteria in the fish intestines depend on feed and environment and most likely bacteria in the faeces interact with the biological water treatment (Holben et al., 2002; Spaangard et al., 2000). Since the waste produced by the fish and the required feed depends on fish type, age and size, the resulting characteristic time of the 


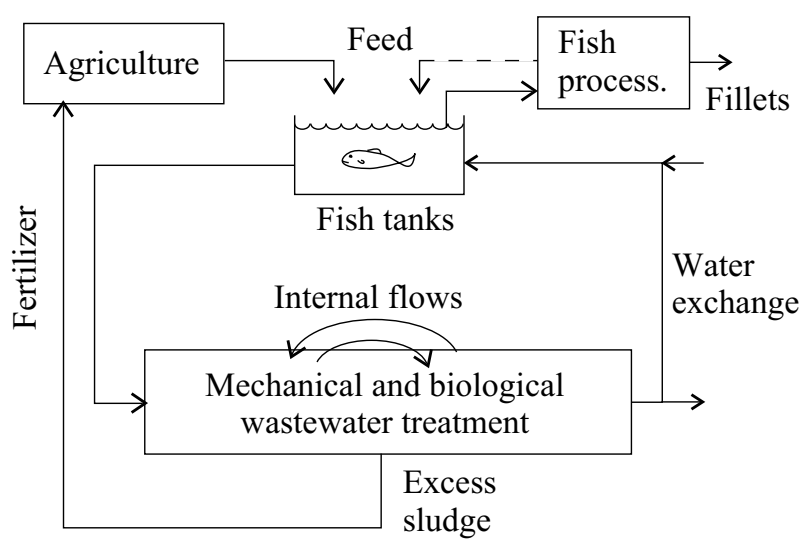

Fig. 1. An illustration of sustainable RAS for herbivore and omnivore species. Note that the return offal (dashed) would be inter species.

system dynamics may range up to several months. To carry out optimisation based on ad hoc assumptions by full or pilot scale experimentation is therefore extremely time consuming and expensive. However, models reasonably validated on experimental data can provide the generality required and, consequently, RAS simulation is likely to become an important tool for selecting experimental setup and for experimental analysis. The complexity of RAS, due to their feedback character and the interactions between water treatment and fish grow-out, implies that in order to optimize a plant (configuration, size, fish, feed, flows etc) with respect to cost, stability robustness and water quality, non-trivial dynamic models of most of the system components are required.

The need for dynamic modelling for deeper insight into aquaculture performance has been identified, and during the last decade there has been a clear development towards the use of models for analysis and simulation of aquacultures. Many of them have their origin in ecological modelling and apply to fish ponds or other systems without designated wastewater treatment processes (Jamu and Piedrahita, 2002; Jimenez-Montealegre et al., 2002; Li and Yakupitiyage, 2003). Because of an aquaculture stand-point, the relatively few studies on land based RAS that consider wastewater treatment use biologically stationary models of the treatment processes, where the efficiency is set to either a fixed percentage removal or a fixed removal rate (e.g. Losordo and Hobbs (2000); Ernst et al. (2000)). However, since the system is dynamic with characteristic times in the same range for fish growth as for water treatment, the dynamics of the biology in the treatment processes, as well as a more diverse waste description, should be included for simulations to be realistic and to further raise the level of understanding.

In this study we show how dynamic models for fish growth, gastric evacuation, feed requirement and nitrogen excretion can be adapted to the state of 
art in advanced dynamic wastewater treatment modelling after some necessary modifications for aquaculture applications. A simulator based on the equations presented has been implemented in Matlab and Simulink (MathWorks, Inc., Natick, MA, USA). It is then used to demonstrate how new improved configurations can be found, increasing the chances of future large-scale production in environmentally sustainable aquaculture systems. It should be noted, though, that for a true plant optimization a thorough model validation and calibration is necessary.

\section{System description}

A land based RAS is typically an assembly of several rearing basins with wastewater led into mechanical and biological wastewater treatment. Generally, fish of different age and size have to be separated due to intra species competition. The fish are therefore graded by size with regular intervals and most fish are then moved one fish tank 'up-size'. Hence, the number of tanks is typically equal to the number of gradings within a production cycle (average interval between fingerling and slaughter). Following every single grading of a complete production line the first tank is restocked with new fingerlings.

In RAS the biological wastewater treatment is often carried out in biofilm reactors, such as trickling filters, biofilters and moving beds. Here, we illustrate with a system of moving beds, though they can be replaced by other types of biofilm reactors with a few modifications of the model equations (Wik, 1999, 2003) and without changing the interface between the model units. In moving bed treatment tanks suspended carriers are entrapped, for example small plastic tubes with fins and a cross inside, such as Kaldnaes/ANOX, on which biofilm develop (Ødegaard et al., 2000). The suspension of the biofilm carriers prevents clogging and because almost all bacteria are attached to the carriers there is no need for sludge recycling as in activated sludge processes.

In aerated moving beds, mixing caused by the air bubbles is generally so vigorous that each reactor tank can be assumed to be completely mixed. Nonaerated tanks are equipped with stirrers to ensure complete mixing. To efficiently achieve low concentrations at least a few moving beds should be placed in series.

The actual function of a biofilm reactor depends only on the specific past and current bacterial environment. This, in turn, is a consequence of the operating conditions and the function of all other units in the RAS, which illustrates the complex dynamics of these systems. It may therefore be premature to denote a reactor as being nitrifying or organics degrading in advance. For example, a temporal increase in feeding regimes may cause an increase in degradable 
organic matter sufficient for heterotrophs to severely outcompete the nitrifying bacteria (Wik and Breitholtz, 1996), resulting in elevated ammonia and nitrite concentrations that could reach toxic levels.

In this study we examine a process configuration aiming for the three main biological treatment steps illustrated in Figure 2. To achieve designated water purification in each reactor is a question not only of dimensioning, but also of dynamic feedback control. Insufficient bioreactor volume or performance in one of the steps may cause a collapse or sub-optimal operation in other units. Although applied to the configuration in Figure 2, the framework of dynamic modelling presented is a tool for carrying out design and dimensioning to achieve a robust performance of any RAS configuration involving biological water purification.

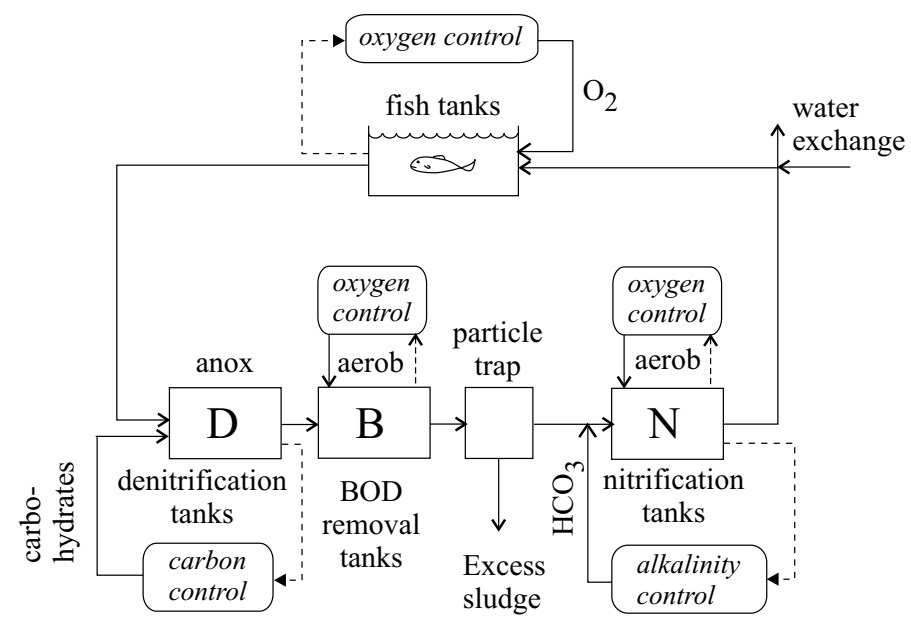

Fig. 2. A schematic picture of main functions aimed for in the RAS example.

Dissolved nitrogen from fish is excreted mainly in the form of urea and ammonia, where ammonia is predominantly excreted by teleost fish (Altinok and Grizzle, 2004; Wright and Land, 1998). Ammonia is nitrified (N) to nitrate with nitrite as an intermediate. In anoxic denitrification (D) facultative heterotrophic bacteria reduce nitrate and nitrite to nitrogen gas by energy and electron capture from biodegradable organic matter. In an aerobic environment these bacteria more efficiently use oxygen for the oxidation of organic matter (B), which further illustrates how a temporal change in operation may cause drastic dynamic changes in the function of the treatment units. Nitrification and denitrification in moving beds used in aquaculture have been demonstrated by Tal et al. (2003), for example.

Biological water treatment results in a bacterial biomass yield. This excess sludge, faeces and feed residues are removed from the system in particle traps, such as drum filters, sand filters or by sedimentation. Suitable locations in the system for such traps vary depending on the application. However, they 
should be placed in such a way that the amount of heterotrophic sludge in the nitrifying reactors is small, since organic material may inhibit the nitrifying efficiency by overgrowth of heterotrophs.

Due to the acidifying effect of nitrification it can sometimes be necessary to add an alkalinity raising compound, otherwise $\mathrm{pH}$ may decrease to levels with an inhibitory effect on the nitrifying performance and fish growth. Therefore, a $\mathrm{pH}$ control loop is applied over the nitrifying reactors in Figure 2. For feeds producing a low $\mathrm{C} / \mathrm{N}$ ratio in the fish waste, addition of an easily biodegradable organic substrate into the anoxic tanks, as indicated in Figure 2, may also be necessary.

\section{Modelling}

All models presented are based on dynamic mass balances. Notation and units follow the standard in wastewater treatment (Grau et al., 1982), with $S$ used for concentrations of soluble substances and $X$ for particulate matter. The variables modelled are the ones used in the first and most widely accepted dynamic activated sludge model (ASM1) (Henze et al., 1987) extended with total phosphorus, $\mathrm{CO}_{2}$ and $\mathrm{NO}_{2}^{-}$(see Table 1). Further extensions to include biological phosphorus removal are straightforward to include in this framework in the same manner as in ASM2 (Henze et al., 2000). The inclusion, however, requires a large amount of new variables and parameters, and is therefore omitted here. 
Table 1

Variables and corresponding Waste Production Matrix*

\begin{tabular}{|c|c|c|c|c|c|c|}
\hline \multirow[b]{2}{*}{$i$} & \multicolumn{2}{|c|}{ Model Variables } & \multicolumn{4}{|c|}{ Waste Production (kg) Matrix } \\
\hline & Not. & Description & $\begin{array}{l}\text { Feed in water } \\
\text { (per kg feed) }\end{array}$ & $\begin{array}{l}\text { Digested feed } \\
\text { (per kg feed) }\end{array}$ & $\begin{array}{c}\text { Fish growth } \\
\text { (per kg fish/d) }\end{array}$ & $\begin{array}{r}\text { Respiration } \\
\text { (per kg fish) }\end{array}$ \\
\hline 1 & $S_{I}$ & Inert soluble organic material & $0.5 I_{\text {Feed }}$ & $0.5 I_{\text {Feed }}$ & $-0.5 I_{\text {Fish }}$ & 0 \\
\hline 2 & $S_{S}$ & Readily biodegradable substrate & $0.3 C O D_{\text {Feed }}$ & $0.3 C O D_{\text {Feed }}$ & $-0.3 C O D_{F i s h}$ & $-0.3 r_{O}$ \\
\hline 3 & $X_{I}$ & Inert particulate organic material & $0.5 I_{\text {Feed }}$ & $0.5 I_{\text {Feed }}$ & $-0.5 I_{\text {Fish }}$ & 0 \\
\hline 4 & $X_{S}$ & Slowly biodegradable substrate & $0.7 C O D_{\text {Feed }}$ & $0.3 C O D_{\text {Feed }}$ & $-0.3 C O D_{\text {Fish }}$ & $-0.3 r_{O}$ \\
\hline 5 & $X_{B H}$ & Active heterotrophic biomass & 0 & $0.3 C O D_{\text {Feed }}$ & $-0.3 C O D_{F i s h}$ & $-0.3 r_{O}$ \\
\hline 6 & $X_{B A}$ & Active autotrophic biomass & 0 & 0 & 0 & 0 \\
\hline 7 & $X_{p}$ & Part. products from biomass decay & 0 & $0.1 C O D_{\text {Feed }}$ & $-0.1 C O D_{F i s h}$ & $-0.1 r_{O}$ \\
\hline 8 & $S_{O}$ & Dissolved oxygen & 0 & 0 & 0 & $-r_{O}$ \\
\hline 9 & $S_{N O}$ & Nitrate and nitrite nitrogen & 0 & 0 & 0 & 0 \\
\hline 10 & $S_{N H}$ & Ammonium and ammonia nitrogen & 0 & $0.7 N_{\text {Feed }}$ & $-0.7 N_{\text {Fish }}$ & 0 \\
\hline 11 & $S_{N D}$ & Soluble biodegradable organic nitrogen & $0.5 N_{\text {Feed }}$ & $0.15 N_{\text {Feed }}$ & $-0.15 N_{F i s h}$ & 0 \\
\hline 12 & $X_{N D}$ & Part. biodegr. organic nitrogen & $0.5 N_{\text {Feed }}$ & $0.15 N_{\text {Feed }}$ & $-0.15 N_{\text {Fish }}$ & 0 \\
\hline 13 & $S_{A l k}$ & Alkalinity (as $\mathrm{HCO}_{3}^{-}$-equivalents) & 0 & 0 & 0 & 0 \\
\hline 14 & $S_{C O 2}$ & Dissolved carbon dioxide & 0 & 0 & 0 & $(44 / 32) r_{O}$ \\
\hline 15 & $S_{P}$ & Phosphorus & $P_{\text {Feed }}$ & $P_{\text {Feed }}$ & $-P_{\text {Fish }}$ & 0 \\
\hline 16 & $S_{\mathrm{NO} 2}$ & Nitrite concentration & 0 & 0 & 0 & 0 \\
\hline 17 & TSS & Total solid substance & - & - & - & - \\
\hline 18 & $Q$ & Flow & - & - & - & - \\
\hline 19 & $K_{L} a$ & Oxygen mass transfer coefficient & - & - & - & - \\
\hline 20 & $L$ & Biofilm thickness & - & - & - & - \\
\hline
\end{tabular}


The models fit into the structure depicted in Figure 3, which is suited for computer implementation.

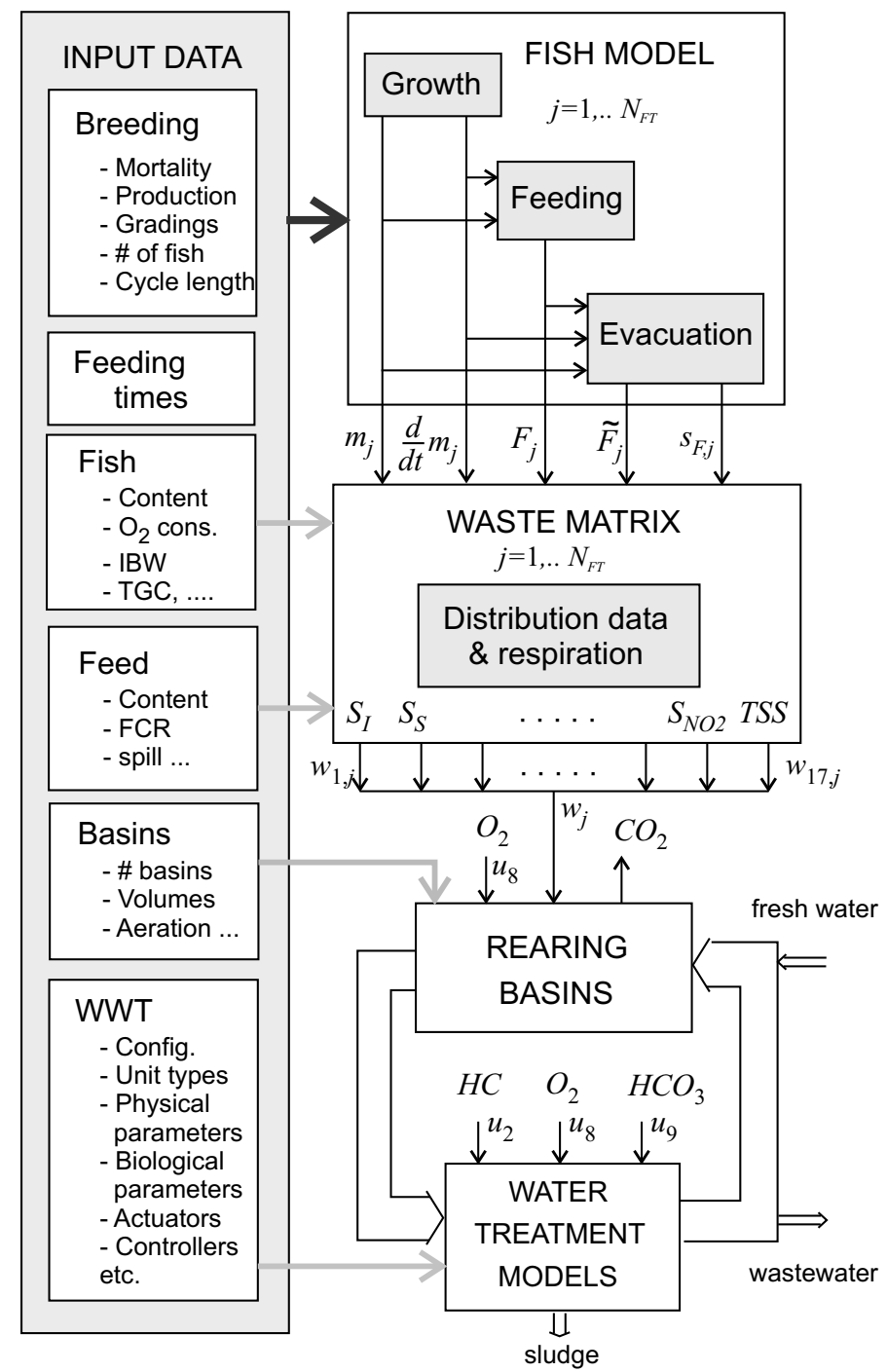

Fig. 3. Information and variable flow in the simulator.

\subsection{Fish Growth and Evacuation}

Soon after fish have been fed, waste production increases to a peak after which it decreases monotonically. As an example, a plot of a waste production after a feeding is depicted in Figure 4. The graph has been generated by a rapid feed ingestion (mathematically a pulse) passing through two first order dynamic systems with time constants $\tau_{1}$ and $\tau_{2}$, and a transport delay $\tau_{d}$, which gives the time $t_{50}=\tau_{1}+\tau_{2}+\tau_{d}$ when half a meal has been evacuated. The smaller of the two time constants essentially determines the increase rate of the 
response and the larger of the two affects mainly the tail. The corresponding gastrointestinal evacuation, for cases when $\tau_{1}$ and $\tau_{2}$ are of about the same magnitude, will have an s-shape as in Figure 4. Such a shape applies for instance to Salmon (Storebakken et al., 1999; Sveier et al., 1999). When $\tau_{1}<<$ $\tau_{2}$ and $\tau_{d}=0$ the evacuation rate approaches an immediate evacuation that decreases exponentially, which applies to Tilapia, for example (Riche et al., 2004).

Expressed in state equations for compound $i$ the evacuation rate model is

$$
\begin{aligned}
\tau_{1} \frac{d}{d t} x_{i}(t) & =-x_{i}(t)+\gamma_{i}\left(1-\epsilon_{\text {Loss }}\right) F\left(t-\tau_{d}\right) \\
\tau_{2} \frac{d}{d t} y_{i}(t) & =-y_{i}(t)+x_{i}(t)
\end{aligned}
$$

where $\epsilon_{\text {Loss }}$ is the fraction of the feed lost into the water column as feed spill, $F$ is the feeding $(\mathrm{kg} / \mathrm{d}), x_{i}$ is a state variable representing a mass accumulation in stomach and intestine, $y_{i}$ is the production rate $(\mathrm{kg} / \mathrm{d})$, and $\gamma_{i}(\mathrm{~kg} / \mathrm{kg}$ feed $)$ determines the proportion of the feed that is converted to waste compound $i$. This state space model is extendable to a finer division of the gastrointestinal system such as the model used by Sveier et al. (1999), for example, by adding new first order states between $x_{i}$ and $y_{i}$. Detailed stochastic stomach modelling has been elaborately treated by Beyer (1998). However, for the purpose of system simulation we are only interested in the aggregated response of all fish in a fish tank. The deterministic model (1) and (2) can then be made stochastic by simply adding a stochastic variable to the feed or to the states as in standard state space modelling for control and signal processing (see for example (Maciejowski, 1989). the stochastic variable is then referred to as noise or disturbance.)

The rate of waste compound $i$ leaving the fish, without correction for growth and respiration, is

$$
y_{i}(t)=\gamma_{i}\left(1-\epsilon_{\text {Loss }}\right) G(p) F(t)
$$

where we define $G$ as the normalized evacuation rate operator, in this case corresponding to the state space model (1) and (2), i.e.

$$
G(p)=\frac{e^{-p \tau_{d}}}{\left(1+p \tau_{1}\right)\left(1+p \tau_{2}\right)}
$$

where $p$ is the derivative operator.

The feed residence time in fish depends on fish size. As a rough estimate we may let $\tau_{1}, \tau_{2}$ and $\tau_{d}$ increase linearly with age. For each modelled compound, 

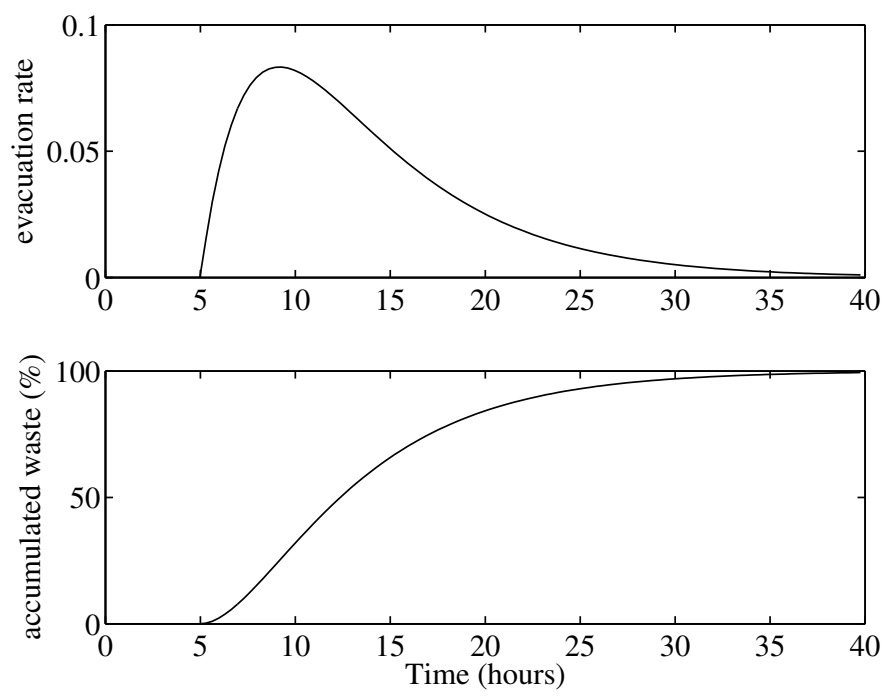

Fig. 4. Normalized evacuation rate (top) and the corresponding accumulated waste (bottom) for a fish modelled with time constants $\tau_{1}=3$ hours and $\tau_{2}=6$ hours and a transport delay $\tau_{d}=5$ hours. In mathematical terms the plots are the impulse and step responses of the evacuation rate transfer operator $G$.

Table 2

Feed and Fish Content $(\mathrm{kg} / \mathrm{kg})^{*}$

\begin{tabular}{l|cc|ccc}
\hline Element & Feed & Fish & COD & $\mathrm{N}$ & $\mathrm{P}$ \\
\hline Protein & 0.44 & 0.174 & 1.45 & 0.16 & - \\
Carbohydrate & 0.14 & 0.002 & 1.10 & - & - \\
Fat & 0.24 & 0.02 & 2.14 & - & - \\
Ash & 0.08 & 0.08 & - & - & 0.20 \\
Water & 0.10 & 0.78 & - & - & - \\
\hline
\end{tabular}

${ }^{*}$ Example: $N_{\text {Feed }}=0.44 \cdot 0.16=0.064 \mathrm{~kg} \mathrm{~N} / \mathrm{kg}$ feed

Fish growth is temperature dependent and one common way to express the 
growth is to use the Temperature Growth Coefficient (TGC) (Chen, 1990):

$$
\mathrm{BW}(t)=\left(\mathrm{IBW}^{1 / 3}+\mathrm{TGC} \cdot T \cdot t\right)^{3} / 1000,
$$

where BW is the fish body weight $(\mathrm{kg})$, IBW is the initial body weight $(\mathrm{g}), T$ is the temperature $\left({ }^{\circ} \mathrm{C}\right)$ and $t$ is the time in days $(\mathrm{d})$. The body weight growth (BWG) in $\mathrm{kg} / \mathrm{d}$ is then:

$$
\mathrm{BWG}(t)=3 \mathrm{TGC} \cdot T \frac{\left(\mathrm{IBW}^{1 / 3}+\mathrm{TGC} \cdot T \cdot t\right)^{2}}{1000}
$$

Due to mortality, the number of fish decreases with age, which is commonly expressed as $p_{M}$ percent of the population per production cycle $t_{p}(\mathrm{~d})$. To numerically simplify we allow the number of fish to be a positive real number (i.e. not necessarily an integer) and assume a first order process of mortality. Then, for an arbitrary time between fingerling and slaughter

$$
n(t)=n(0) e^{-k t}
$$

where $n(0)$ is the initial number of fish and $k$ is the first order mortality coefficient $(1 / \mathrm{d})$, which relates to $p_{M}$ as

$$
k=-\frac{1}{t_{p}} \ln \left(1-\frac{p_{M}}{100}\right)
$$

The total fish mass in each tank is

$$
m_{j}(t)=\mathrm{BW}_{j}(t) n_{j}(t), \quad j=1,2, \ldots N_{F T},
$$

where $m_{j}$ is the fish mass $(\mathrm{kg})$ in fish tank $j$, and $N_{F T}$ is the number of fish tanks.

The respiration rate of a fish, which can be expressed as $\mathrm{gO}_{2} /(\mathrm{kg}$ fish and $\mathrm{d})$, is a fairly well known quantity. Carbon dioxide production is approximately equal to the respiration rate of oxygen. Hence, using the mass determined by Eq. (7), we can estimate how much of the carbon (COD) that is lost in respiration.

The amounts of carbon (COD), $\mathrm{N}$ and $\mathrm{P}$ accumulating in the fish can be determined from the corresponding contents in the fish (2) and the mass growth $(\mathrm{kg} / \mathrm{d})$ in each tank, i.e.

$$
\frac{d}{d t} m_{j}(t)=n_{j}(t) \frac{d}{d t} \mathrm{BW}_{j}(t)+\mathrm{BW}_{j}(t) \frac{d}{d t} n_{j}(t)
$$




$$
=n_{j}(t)\left(\mathrm{BWG}_{j}(t)-k \mathrm{BW}_{j}(t)\right)
$$

Note that other growth models may equally be used as long as they predict mass and mass growth, see Figure 3.

\subsection{Feed}

Feed conversion ratio (FCR) is the amount $(\mathrm{kg})$ of feed required per fish mass increase $(\mathrm{kg})$, and it varies significantly with feed, fish species and size. Based on the FCR (feed/fish growth) the amount of feed per day required in each tank is determined by multiplication of the mass growth with FCR.

Some of the feed is not biodegradable, but has to be considered inert. To conform with the units used in water treatment, this inert material is expressed as COD and is subtracted from the COD content determined from Table 2. A low default value of $3 \%$ for the fraction of feed being inert has been assumed.

\subsection{Waste Production}

The production of the waste constituents in Table 1 in each fish tank during a period between two gradings can now be determined as follows:

(1) The fish body weight $\left(\mathrm{BW}_{j}\right)$ immediately after a grading can, for example, be determined from (4) evaluated for $t=t_{g}, 2 t_{g}, \ldots, N_{F T} t_{g}$, where $t_{g}=$ $t_{p} / N_{F T}$ is the time between two consecutive gradings.

(2) The number $n_{j}(0)$ of fish in each tank $(j)$ immediately after grading is determined by (5) evaluated at $t=t_{g}$.

(3) The mass $m_{j}(t)$, the mass growth $d m_{j}(t) / d t$ and the feeding $F_{j}(t)$ in each tank is calculated using (4) to (8), $\mathrm{FCR}_{j}$ and the specified feeding times (e.g. 06:00-06:15 and 18:00-18:15).

(4) The 'digested' feed $\tilde{F}_{j}(t)=G_{j}(p) F_{j}(t)$ in each tank is calculated.

(5) An evacuation rate signal $s_{F, j}(t)=G_{j}(p) \delta_{j}(t)$ is determined for reasons to be explained. Here, $\delta_{j}(t)$ is a pulse that is zero whenever $F_{j}$ is zero and otherwise $1 /$ (number of feedings a day $\times$ feeding duration) such that the integral over one day is unity.

(6) The net production $w_{j}$ of waste in each tank as function of time can be calculated, using the waste production matrix (see Table 1), as the sum of 


$$
\begin{aligned}
\text { column } 1 \times F_{j}(t) \epsilon_{\text {Loss }} \\
\text { column } 2 \times \tilde{F}_{j}(t)\left(1-\epsilon_{\text {Loss }}\right) \\
\text { column } 3 \times s_{F, j}(t) d m_{j}(t) / d t \\
\text { column } 4 \times s_{F, j}(t) m_{j}(t)
\end{aligned}
$$

If it is assumed that under normal circumstances the respiration rate is not significantly coupled to intestine activity, columns 3 and 4 should not be multiplied by the feed signal $s_{F}$ for oxygen and carbon dioxide.

Table 1 deserves some comments. After feeding, an atom in the feed has four possible outcomes: (i) Not consumed by the fish, (ii) digested and excreted, (iii) digested and assimilated, or (iv) digested and respired. The first column of the waste production matrix describes how feed lost into the water is dispersed into the modelled compounds. Note that the feed may contain organic components that are not biodegradable, but have to be considered inert. These inert fractions are subtracted from the COD feed defined by Table 2, and what remains is the $C O D_{F e e d}$ used in Table 1 . The second column defines how the evacuated waste is distributed after passage through the intestines, i.e. the elements in the second column define $\gamma_{i}$ in Eq. (3). The third column represents mass accumulation in the fish, where the content of COD, N and P in fish can be determined in the same manner as for the feed, i.e., based on the content of protein, fat, carbohydrate, water and ash. For the distribution of the digested feed on the modelled constituents to remain as given in column 2 , the coefficients in column 3 should be the same as in the second column but with opposite sign (cf. Table 1).

The last column accounts for loss by respiration. Also here the coefficients for the COD components should be the same as in columns 2 and 3 in order not to change the component distribution of the waste.

Further, for the mass balances to be correct the coefficients for each elemental component (N, COD, P and I) should add up to unity in columns 1, 2 and 3. The correction coefficients in column 4 of the produced COD due to respiration should also add up to unity. The production of carbon dioxide is here assumed to be one $\mathrm{CO}_{2}$ for every respired $\mathrm{O}_{2}$, hence the factor $44 / 32$ in Table 1.

Columns 3 and 4 are multiplied with the evacuation rate signal $s_{F, j}$ to avoid a negative production of waste (except for oxygen). Since fish growth and respiration mathematically result in negative contributions to the waste production, the production would otherwise become negative after the digested feed has been evacuated. Multiplying with $s_{F, j}(t)$ forces the reduction in produced waste to follow the same dynamic response as the digested feed, hence avoiding negative waste production. 
Note that the coefficients in columns 2, 3 and 4 must not be equal as recommended above. Changing the coefficients in columns 3 and 4 corresponds to a change in waste composition correlated to fish growth and mass. Further, if the stoichiometric relation between respired $\mathrm{O}_{2}$ and $\mathrm{CO}_{2}$ does not equal one the coefficients in column 4 should also be changed accordingly.

\subsection{Rearing Basins}

The fish tanks are assumed to be well mixed and the mass balance for component $i$ is then

$$
V \frac{d}{d t} Z_{i}=Q\left(Z_{i, i n}-Z_{i}\right)+w_{i}+u_{i}
$$

where $Z_{i}$ denotes either soluble concentration $S_{i}$ or particulate concentration $X_{i}, Z_{i, i n}$ is the concentration in the tank influent, $w_{i}$ is the produced waste of compound $i$, and $u_{i}$ is the amount of externally added or removed matter.

Oxygen may either be introduced as a (liquid) addition to the tank influent, i.e. $u_{8}=\dot{m}_{O_{2}} \mathrm{~g} / \mathrm{d}$, or by aeration. In case of aeration, a standard gas transfer model may be used:

$$
\begin{aligned}
u_{8} & =V K_{L} a_{O_{2}}\left(S_{O_{2}, s a t}-S_{8}\right) \\
u_{14} & =V K_{L} a_{C O_{2}}\left(S_{C O_{2}, s a t}-S_{14}\right)
\end{aligned}
$$

where the mass transfer coefficient $K_{L} a_{O_{2}}$ depends on the aeration method, the air flow rate and bulk characteristics. By default, a ratio $K_{L} a_{C O_{2}} / K_{L} a_{O_{2}}=0.9$ is used (Royce and Thornhill, 1991).

\section{Moving Beds}

All the moving bed reactors are modelled identically, except for the attachment and detachment rates that are set slightly lower if the biofilm in the simulations turns out to be mainly autotrophic rather than heterotrophic. The beds are modelled as biofilm reactors with biofilm fixed on carriers and with suspended sludge in the bulk water. Due to lack of knowledge, and the fact that the movement of the carriers enhances mass transfer, the biofilm is assumed to be homogenous in the sense that, on average, concentrations and bacterial distribution are the same at all depths of the biofilm. The processes, stoichiometry and kinetics are based on the Activated Sludge Model (ASM) no. 1 (Henze et al., 1987), i.e. we consider aerobic and anoxic growth of heterotrophs, 
aerobic growth of autotrophs, decay of heterotrophs and autotrophs, ammonification of soluble organic nitrogen and hydrolysis of entrapped organics and entrapped organic nitrogen. A few modifications have been made to suit aquaculture application:

(i) The concentrations of $\mathrm{CO}_{2}, \mathrm{P}$ and $\mathrm{NO}_{2}$ have been added as variables.

(ii) The nitrification rate has been changed to depend on the alkalinity as in the models ASM2 and ASM3 (Henze et al., 2000), and nitrifying biofilm applications (Wik, 1999).

(iii) As in ASM3 a Monod factor w.r.t. ammonium has been included in the growth of heterotrophs to avoid negative ammonium concentrations.

(iv) Nitrite oxidation by NOB has been included by modelling the nitrite concentration either by worst case or by balanced growth (Boller and Gujer, 1986).

Let $X_{i, b}$ and $S_{i, b}$ denote the concentrations of particulates and solutes in the bulk water phase, and $X_{i, c}$ and $S_{i, c}$ denote the corresponding concentrations in the biofilm attached to the carriers. The transfer of particulates $\left(\mathrm{g} / \mathrm{m}^{2} \mathrm{~d}\right)$ from the bulk to the biofilm is assumed to be

$$
J_{i}=K_{a} X_{i, b}-K_{d} L^{2} X_{i, c}, \quad i=3,4,5,6,7,12
$$

where $K_{a}$ is the attachment rate coefficient, $K_{d}$ is a detachment rate coefficient and $L$ is the biofilm thickness. Maurer et al. (1999) model a moving bed reactor with a detachment proportional to the concentration only. However, this may result in an unbounded growth. Introducing a dependence on $L$, such that the thicker the biofilm the easier bacteria and other particulates detach, causes a stability in the sense that the biofilm thickness does not vary as much. From extensive testings a linear dependence was not found to be enough to give realistic variations but a squared biofilm thickness was sufficient. The resulting detachment rate is then equal to what is common in models of fixed biofilms (Wik, 1999).

The flux of solutes $\left(\mathrm{g} / \mathrm{m}^{2} \mathrm{~d}\right)$ from the bulk to the biofilm is assumed to be driven by the difference between the concentrations in the film and in the bulk, i.e.

$$
J_{i}=K_{x}\left(S_{i, b}-S_{i, c}\right), \quad i=1,2,8 \ldots 11,13 \ldots 16 .
$$

The mass transfer coefficient $K_{x}$ is assumed to be the same for all solubles and since convection dominates diffusion in the transfer from bulk to biofilm surface as the carriers are moved within the bulk.

With $V_{w}$ denoting the empty reactor bed volume minus the volume of the carriers without biofilm, a mass balance for component $i$ in the bulk phase gives 


$$
\begin{aligned}
\frac{d}{d t}\left(V_{w}-L A\right) Z_{i, b}= & Q\left(Z_{i, i n}-Z_{i, b}\right)-A J_{i} \\
& +J_{i, g}+\left(V_{w}-L A\right) r_{i}\left(Z_{b}\right)
\end{aligned}
$$

where $A$ is the total area of biofilm in the reactor, $Z_{i, i n}$ is the influent concentration, $J_{i, g}$ is the flux $(\mathrm{g} / \mathrm{d})$ from gas phase or the surrounding air to the bulk, and $r_{i}$ is the observed conversion rate (ASM1-ASM3). $J_{i, g}$ is zero for all components except oxygen and carbon dioxide, and then only in the aerated reactors. In the aerated moving bed reactors the transfer of oxygen and carbon dioxide is modelled in the same way as described for the fish tanks:

$$
\begin{aligned}
J_{8, g} & =\left(V_{w}-L A\right) K_{L} a_{O_{2}}\left(S_{O_{2}, s a t}-S_{8}\right) \\
J_{14, g} & =\left(V_{w}-L A\right) K_{L} a_{C O_{2}}\left(S_{C O_{2}, s a t}-S_{14}\right)
\end{aligned}
$$

Since the mass transfer coefficient depends on the air flow rate and bulk characteristics, $K_{L} a$ is generally not constant but a manipulative variable used in feedback control, for example.

Mass balances for the biofilm give

$$
\begin{aligned}
\frac{d}{d t} A \epsilon L S_{i, c} & =A J_{i}+A L r_{i}\left(Z_{c}\right) \\
\frac{d}{d t} A L X_{i, c} & =A J_{i}+A L r_{i}\left(Z_{c}\right)
\end{aligned}
$$

where we note that the concentrations of solutes are defined only for the void volume in the biofilm, while the concentrations of particulates are defined for the biofilm as a whole. The biofilm thickness will then vary according to

$$
\frac{d}{d t} A(1-\epsilon) \rho_{X} L=\sum_{i=3}^{7} A J_{i}+A L r_{i}\left(Z_{c}\right)
$$

where $\epsilon$ is the biofilm porosity and $\rho_{X}$ is the biofilm density $\left(\mathrm{gCOD} / \mathrm{m}^{3}\right)$. Applying the chain rule to the mass balances gives the following state equations for one moving bed reactor tank:

$$
\begin{aligned}
\frac{d}{d t} Z_{i, b} & =\frac{Q Z_{i, i n}+\left(A \frac{d}{d t} L-Q\right) Z_{i, b}-A J_{i}+J_{i, g}}{V_{w}-L A}+r_{i}\left(Z_{b}\right) \\
\frac{d}{d t} S_{i, c} & =\frac{1}{L}\left(\frac{J_{i}}{\epsilon}-S_{i, c} \frac{d}{d t} L\right)+\frac{r_{i}\left(Z_{c}\right)}{\epsilon} \\
\frac{d}{d t} X_{i, c} & =\frac{1}{L}\left(J_{i}-X_{i, c} \frac{d}{d t} L\right)+r_{i}\left(Z_{c}\right)
\end{aligned}
$$




$$
\frac{d}{d t} L=\frac{1}{\rho_{X}(1-\epsilon)}\left(\sum_{i=3}^{7} J_{i}+L r_{i}\left(Z_{c}\right)\right)
$$

\section{Simulation}

A simulator for simulation of recirculating aquaculture systems of this type was developed for a Matlab environment, using the Simulink and Control toolboxes (MathWorks, Inc., Natick, MA, USA). The simulator can be applied to any combination of fish, feed and treatment provided the required data for the plant is given. The data for the treatment tanks that has to be provided by the user are the number of tanks, their volume and filling. The configuration of the plant, i.e. placement of the biofilm reactors, the pumping tanks, the rearing basins, particle traps, flow split and flow merge are set using the graphical user interface in Simulink. To make the simulations up to speed, the dynamic model units for the fish basins and moving beds have been implemented as c-code S-functions.

Basically, the necessary fish and feed data (see Figure 3) are

(1) The content of the feed and the fish (see Table 2).

(2) The initial body weight of the fish (fingerling).

(3) The time between grading of the fish and the length of the production cycle.

(4) The oxygen consumption rate.

(5) The feed conversion ratio and the times of the feeding.

(6) Initial fish density $\left(\mathrm{kg} / \mathrm{m}^{3}\right.$ fish tank).

(7) Fish tank volumes (or production) and water temperature.

(8) Rough estimates of the proportions of different organic compounds in the feed and in the faeces (the coefficients in columns 1 and 2 in Table 1).

(9) Rough estimates of the time constants for the gastric evacuation (see Figure 4).

The parameter values for the wastewater treatment and their temperature dependence have been collected and derived from the ASM2, ASM3 (Henze et al., 2000), the COST benchmark implementation of ASM1 (Copp, 2001), and the nitrification and biofilm parameter values used by Maurer et al. (1999) and Wik (1999). 
In the simulator a few PI-control loops have been implemented either for the actual regulation of the plant or to achieve equal conditions for fair comparisons between different plant sizes and configurations. In addition to aeration control in the aerated treatment tanks there is oxygen control either by liquid oxygen or by aeration, alkalinity control and, if required, addition of an external carbon source for the denitrification by feedback of either the nitrate or the oxygen concentration. To avoid tedious tuning of the controllers every time the system or a parameter value is changed, e.g. in an optimization, automatically tuned regulators are almost indispensable. Such automatically tuned controllers were analytically prepared based on mass balances and stoichiometry to give expressions how to scale the gain and integration time appropriately with flow, volumes, bacterial yield and oxygen saturation concentration. The controllers are therefore robust to most changes to the system.

\section{Case Study}

To illustrate results achievable with the integrated dynamic wastewater and aquaculture modelling we have simulated a system for 100 tonnes annual production of rainbow trout with 14 parallel rearing tanks and a production cycle of 30 days. Rainbow trout has been chosen because of the relatively well documented data for salmonids and their hard water quality requirement compared to other commonly aquacultured species, such as Clarias and Tilapia.

There are many different configurations of RAS, though generally the wastewater treatment is focused on TSS removal and either nitrification alone or nitrification and denitrification. Such treatment strategies generally result in high concentrations of either nitrate, or ammonium and organic solutes, and a large water exchange rate is usually required with a consequent large nutrient discharge. For intense aquaculture of relatively sensitive fish species, such as rainbow trout, both well functioning nitrification and denitrification are required. The configuration in Figure 2 has the potential to achieve an efficient nitrogen removal with small amounts of additives. First, the fish tank effluent is treated anaerobically to achieve deoxygenation and subsequent denitrification. This is followed by an aerobic treatment, where excess organic substrate is consumed and finally, the ammonium is nitrified to nitrate. The reverse order, i.e. to begin with aeration and end with anoxic denitrification is common and has the advantage that the risk of elevated toxic nitrite concentrations in the treated water is small. However, it implies that almost all available organic substrates in the fish waste must be degraded in the initial aerobic section in order for the nitrifiers not to be outcompeted by heterotrophs. Such an order 
of operation therefore requires a substantial addition of easily biodegradable substrates for an efficient subsequent anaerobic denitrification.

In the simulations presented here two anaerobic moving beds were used, followed by four aerobic beds with a sand filter placed after the first aerobic bed. The sand filters have a presumed particulate removal efficiency of $80 \%$. However, the simulations presented are not sensitive to this efficiency as long as it is reasonably high. All the moving beds were filled to $70 \%$ with Kaldnaes $\mathrm{K} 1$ carriers having a specific surface area of $500 \mathrm{~m}^{2} / \mathrm{m}^{3}$ (Rusten et al., 2000). The water exchange cannot be set to zero because the inert matter that can neither be removed mechanically nor be biodegraded, still has to be removed. Therefore, the exchange was set to $30 \mathrm{~m}^{3} / \mathrm{d}$, which corresponds to about $1 \%$ of the total volume.

The data used for the fish are presented in Tables 1 and 2, and Figure 4. How the digested nitrogen is fractionated between the modelled compounds is fairly well documented for many fish species and types of feed (Altinok and Grizzle, 2004; Dosdat et al., 1996; Wright and Land, 1998; Piedrahita, 2003), but the distribution of organic material is a more complex problem. However, based on a stoichiometry between TSS and COD (Copp, 2001), the total COD waste production, and the data for TSS, $\mathrm{BOD}_{5}, \mathrm{COD}$ and $\mathrm{BOD}_{20}$ reviewed by Chen et al. (1997), the proportions in Table 1 were deduced. Identified bacteria in the intestines vary depending on location, size, environment and feed (Holben et al., 2002), though we assume all being heterotrophic due to their competitiveness in the intestinal lumen.

Water quality criteria have been extensively studied. However, the threshold values vary somewhat between different sources due to differences in fish size and experimental conditions. The target water quality criteria in this case was set to $10 \mathrm{gCO}_{2} / \mathrm{m}^{3}, 3.5 \mathrm{gN}-\mathrm{NH}_{4}$ (pH6.5), 25-80 gTSS $/ \mathrm{m}^{3}, 0.02 \mathrm{gN}-\mathrm{NO}_{2} / \mathrm{m}^{3}$, $3 \mathrm{gN}-\mathrm{NO}_{3} / \mathrm{m}^{3}$ and $5-8 \mathrm{gO}_{2} / \mathrm{m}^{3}$ (Noble and Summerfelt, 1996; Gebauer et al., 1991; Camargo et al., 2005; Ip et al., 2001). The oxygen concentration was regulated by aeration to a setpoint of $5 \mathrm{gO}_{2} / \mathrm{m}^{3}$, and because of the aeration the carbon dioxide concentration never exceeded the threshold value.

\section{Results and Discussion}

The resulting mass balances for the waste production in the rearing basins are presented in Table 3, where we can note that a significant amount of the carbon is lost in respiration.

To achieve a quasi-steady state, in the sense that two succeeding production cycles closely resembles one another for all investigated variables, required 
Table 3

Average distribution in $\mathrm{kg} / \mathrm{d}$

\begin{tabular}{l|llll}
\hline & Added & Waste & Fish & Respiration \\
\hline $\mathrm{COD}$ & 388 & 104 & 80 & 204 \\
$\mathrm{~N}$ & 21.5 & 13.7 & 7.8 & 0 \\
$\mathrm{P}$ & 4.9 & 3.5 & 1.4 & 0 \\
\hline
\end{tabular}

about 12 production cycles (one year), which can be deduced from a mass balance for the inert variables $S_{I}$ and $X_{I}$. The simulation time on a Dell Pentium (R) 4 CPU $2 \mathrm{GHz}$ with $1 \mathrm{~GB}$ RAM is then approximately 15 minutes. However, 4 to 5 cycles suffice if only the substrates and active bacteria are considered. Figure 5 illustrates the dynamics of the investigated system with twice daily feeding for the period between two gradings. Immediately after grading the fish, the waste load decreases because of the replacement of large fish with fingerlings and a corresponding decrease in feeding ration. As a consequence the nutrient concentrations rapidly drop. This is followed by a decrease in the amount of active bacteria, because of lowered kinetic rates with lower substrate concentrations. After some time the increased load, as a consequence of the increased fish mass, causes an increase in bulk concentrations as well as in the amount of bacteria. Evidently, the disturbance of the system caused by the grading results in dynamic transients that affect the system during the entire production cycle.
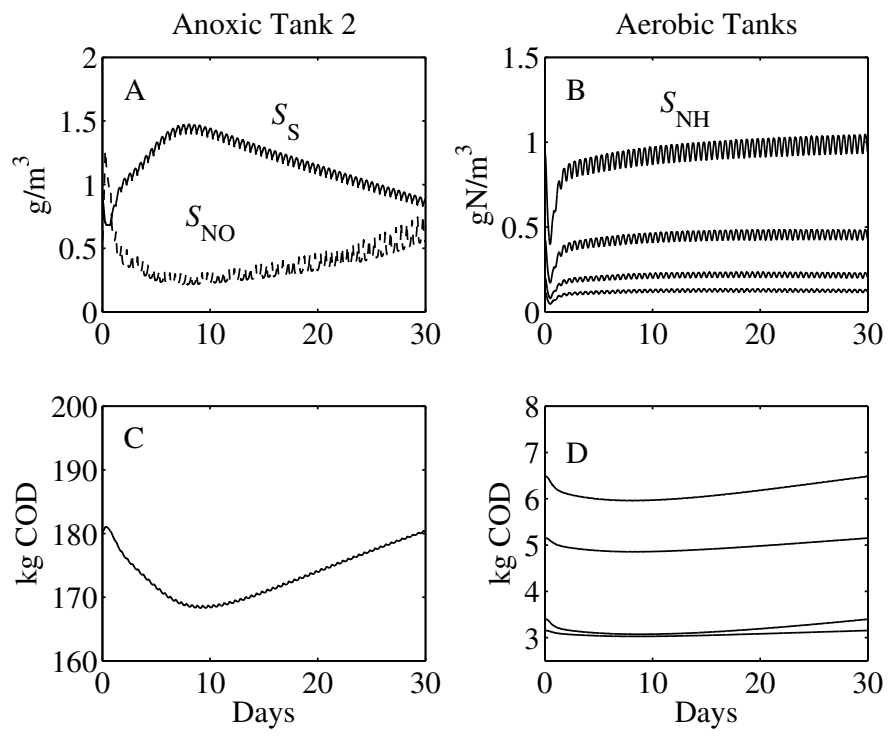

Fig. 5. Concentrations of nitrate and dissolved easily biodegradable organic matter (A) and amount of heterotrophic bacteria (C) in the second anoxic bed. Concentrations of ammonium (B) and amount of autotrophic bacteria (D) in the aerated beds. The rapid oscillations are caused by the twice daily feeding. 
In the simulated RAS the waste from the rearing basins does not contain enough soluble biodegradable substrate to denitrify all the nitrate produced in the nitrification. Addition of an external carbon source, which could be derived from fermented sludge, is therefore necessary. In Table 4 (case 1) the concentrations on the last day of the period are listed. All simulated values (both case 1 and case 2) have been generated with a constant addition of $11 \mathrm{KgCOD} /$ day to the first anoxic tank. Replacing this constant addition with a PI feedback controller adding substrate based on the nitrate concentration in the last anoxic tank turned out to be troublesome in two ways. The first is entirely numerical and caused by the fact that the simulated system is by its nature very stiff due to the large span in time constants, which can be less than a minute for solutes in the biofilm and several days for the bacteria (Kissel et al., 1984; Wik, 1999).

The other problem is not numerical but an effect of the recirculation, which makes the nitrate control cause large fluctuations in the system. A well behaved PI feedback controller adding substrate can be derived analytically when ignoring the effects of recirculation. Applying the controller on an open loop system, where we use the previous fish tank effluent (with constant substrate addition) as influent to the anoxic tanks, results in a stable behavior, which is illustrated in Figure 6a by a step response to an increase in nitrate concentration from the fish basins. Using the same controller in the recirculated system gives a highly resonant behavior (see Figure 6b). This illustrates a built-in problem of RAS, that fluctuations in the system can be triggered by the recirculation in combination with the system dynamics if the plant is not properly designed and operated. The reason why the oxygen control in the rearing basins do not cause such a problem is that the oxygen concentration in the fish basin influents is not really affected by the aeration in the fish tanks. Nitrate on the other hand is only used in denitrification, and therefore a change in the operating conditions for denitrification will also have a long-term effect as the water has passed one cycle of recirculation. In this case the problem illustrated in Figure $6 \mathrm{~b}$ is even more accentuated if the controller gain is lowered, contradictory to what is the normal case in control (normally controller induced oscillations are reduced by a decreased gain). In fact, a solution to this problem is to apply rapid control because if the nitrate concentrations are kept reasonably close to the setpoint, the disturbance caused by the recycled nitrate concentration will be easier to handle. 

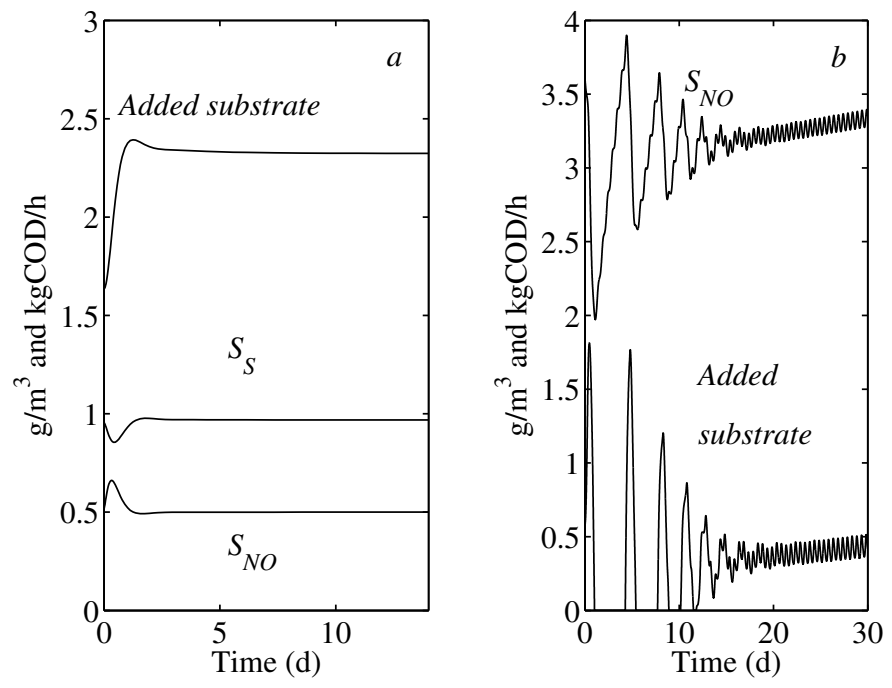

Fig. 6. Step responses to an increase in nitrate concentration from the fish basins: (a) Added substrate and concentrations of easily biodegradable organic matter and nitrate in the (second) denitrifying bed using a PI controller and no recirculation. (b) Added substrate and nitrate concentration in the fish basins using the same PI-controller on the recirculated plant. 
Table 4

Selected bulk concentrations day 29. In Case 1 the configuration is the one in Figure 2 and in Case 2 a bypass over the last three moving beds $(\mathrm{N})$ has been introduced

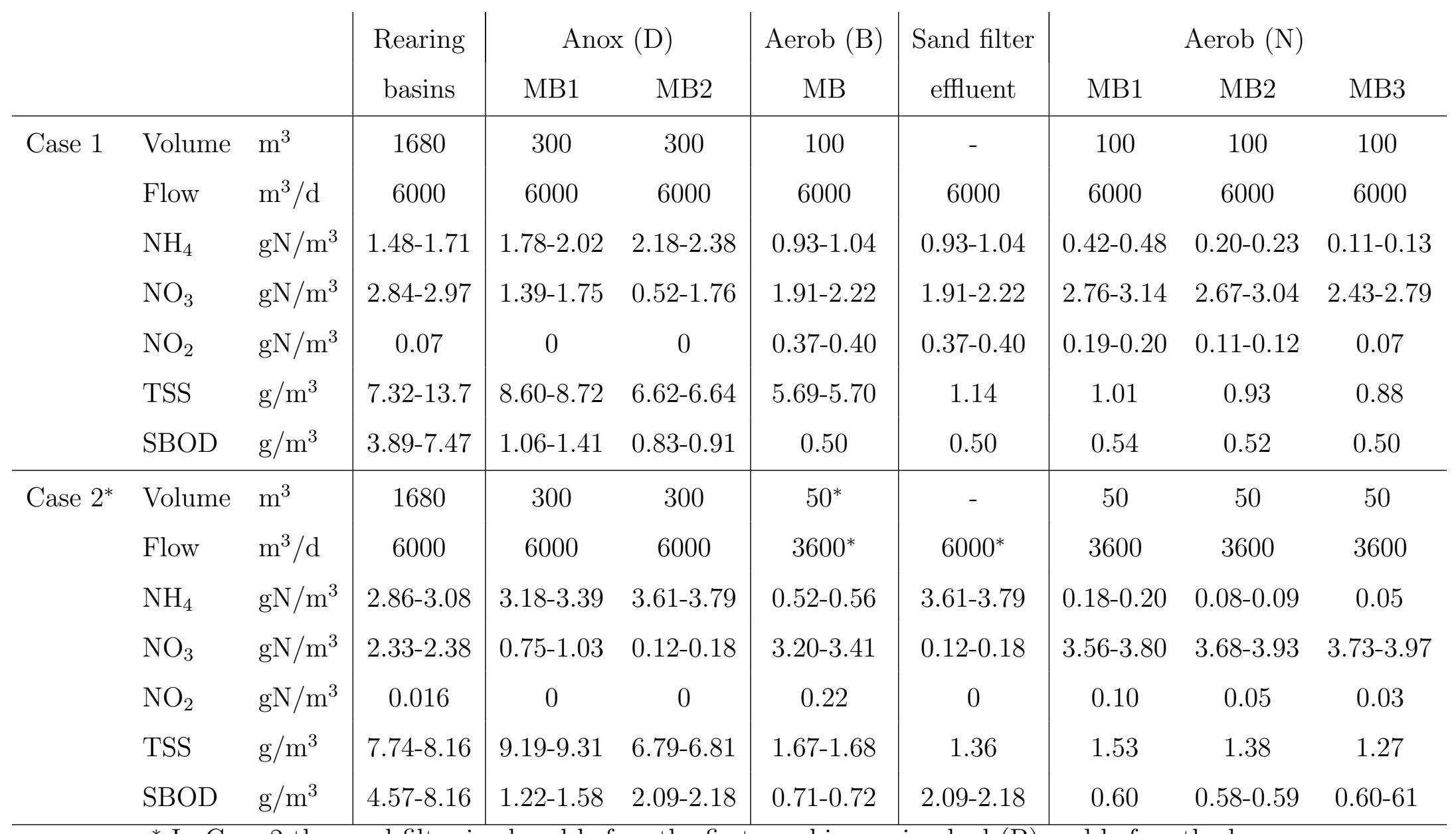

* In Case 2 the sand filter is placed before the first aerobic moving bed (B) and before the bypass 
Nitrite management is one of the most critical variables for control in RAS even at sublethal concentrations. A related qualitative result from the dynamic simulations is that increasing the volumes of the nitrifying beds lower the nitrite concentration but only to a certain extent. A target concentration below $0.05 \mathrm{gN}-\mathrm{NO}_{2} / \mathrm{m}^{3}$ could, for example, not be achieved with reasonable volumes (see Figure 7.) In order to reach low nitrite concentrations nitrification has to be nearly complete. This implies that for a given hydraulic residence time the ammonium concentration must also be very low. However, low ammonium concentrations means poor growth conditions for the nitrifiers and hence less bacteria can be sustained. As a result the lowest nitrite and ammonium concentrations will occur very soon after a grading (c.f. Figure 5b). However, since the amount of nitrifiers will decrease as a result of poor growth conditions (low concentrations), both the ammonium and the nitrite concentrations will soon increase again. Somewhat surprising, the highest nitrite and ammonium concentrations in the fish basins are not at the end of the cycle, when the load is at its maximum, but due to the dynamics they reach their maxima somewhere in the middle of the cycle.

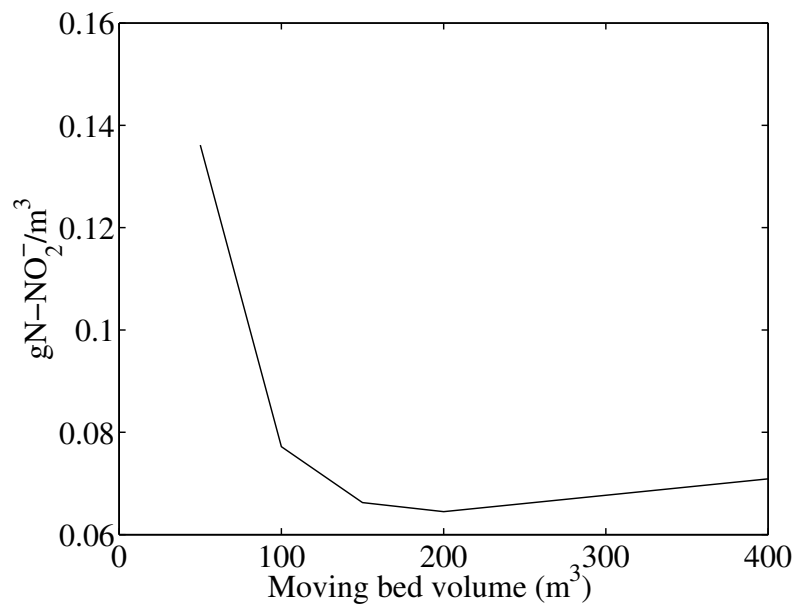

Fig. 7. Nitrite concentration in fish basins as a function of aerated moving bed (N) volume

To meet water quality criteria with nitrite concentrations below $0.05 \mathrm{gN}$ $\mathrm{NO}_{2} / \mathrm{m}^{3}$ a new configuration, where the aerated moving beds are partly bypassed, was investigated (Case 2 in Table 4). As can be seen from the table, not only could the nitrite concentration be lowered below $0.02 \mathrm{gN}-\mathrm{NO}_{2} / \mathrm{m}^{3}$ but this could also be achieved with only half the nitrifying treatment volume. The reason is that a higher ammonium concentration can be accepted in the nitrifying moving beds, which in turn render higher nitrification rates and hydraulic retention time, allowing more time for complete nitrification to occur. Without this bypass a hampered nitrification, caused by an excess of dissolved organics for example, will easily cause elevated nitrite concentrations. With the bypass, an increase in nitrite concentration can be counteracted by increasing the bypass. Furthermore, the reactor volumes for aerobic degrada- 
tion of organic matter could also be lowered because only the nitrified stream requires low concentrations of organic substrate. For species more tolerant to ammonia, these advantages of a bypass will be even more pronounced.

\section{Conclusions}

Aquaculture has been growing annually by nearly 10\% per year since 1970 with a consequent impact on the environment (FAO, 2007). Environmental damages related to traditional aquaculture in open cages and ponds can be avoided with land based recirculating aquaculture systems (RAS). However, for these systems to become competitive they need to be robust and, at least to some degree, economically optimized. RASs are highly complex because of the interactions between the water treatment, the feed and the fish. The inherently slow biology involved also implies that experimental testing alone is tedious and costly, which hamper the development. This calls for means to simulate such systems.

Here, a framework for integrating fish growth modelling with advanced dynamic wastewater treatment modelling has been presented. The key elements in the integration are

- Dynamic component balances for carbon, nitrogen, phosphorous, inert substances and oxygen, based on feed and fish content, feeding, fish mass, fish mass growth, respiration and evacuation.

- A dynamic evacuation rate model (evacuation rate operator).

- A Waste Production Matrix, giving a rough estimate of how the components $(N, C O D, P, I)$ in the waste are distributed on the wastewater treatment model variables.

The basis for the wastewater treatment models is the widely accepted activated sludge models by the International Water Association (IWA), extended with variables for carbon dioxide and nitrite, which are needed in an aquaculture application. The kinetics were implemented in a model derived for moving bed biofilm reactors.

The methodology has been illustrated by implementation in a simulator, and simulation of a recirculating aquaculture system for rainbow trout. From the simulations it is concluded that (i) the entire plant should be considered as a dynamic system. Neither the rearing part nor the water treatment part should be modelled as stationary. (ii) Controlling the addition of hydrocarbons for denitrification by feedback of the nitrate concentration may cause oscillations due to the recirculation. (iii) With a straightforward one line predenitrification structure sufficiently low nitrite levels may be difficult to obtain. (iv) 
Introducing a by-pass over the nitrifying units improved the performance considerably. Not only could the nitrite levels be reduced by $75 \%$ but the by-pass also introduce a degree of freedom that can be used for keeping the nitrite concentration below safe target levels. The new configuration also allowed the reactor volumes to be reduced.

Though a model validation and calibration is needed for a true optimization, the demonstrated case study have illustrated the importance of an integrated dynamic aquaculture and wastewater treatment modelling, for the understanding and guidance towards new and improved RAS solutions.

\section{References}

Altinok, I., Grizzle, J., 2004. Excretion of ammonia and urea by phylogenetically diverse fish species in low salinities. Aquaculture 238, 499-507.

Beyer, J., 1998. Stochastic stomach theory of fish: an introduction. Ecological modelling 114, 71-93.

Boller, M., Gujer, W., 1986. Nitrification in tertiary trickling filters followed by deep-bed filters. Wat. Res. 20 (11), 1363-1373.

Camargo, J., Alonso, A., Salamanca, A., 2005. Nitrate toxicity to aquatic animals: a review with new data for freshwater invertebrates. Chemosphere 58, 1255-1267.

Chen, C. Y., 1990. Fish nutrition, feeds, and feeding with special emphasis on salmonid aquaculture. Food Reviews International 6, 333-357.

Chen, S., Coffin, D., Malone, R., 1997. Sludge production and management for recirculating aquaculture systems. J. World Aquaculture Society 28 (4), 303-315.

Copp, J. B., 2001. The COST Simulation Benchmark: Description and Simulator Manual. COST Action 624 and COST Action 682, http://www.ensic.inpl-nancy.fr/COSTWWTP/.

Dosdat, A., Servais, F., Metailler, R., Huelvan, C., Desbruyeres, E., 1996. Comparison of nitrogenous losses in five teleost fish species. Aquaculture 141, 107-127.

Ernst, D. H., Bolte, J. P., Nath, S. S., 2000. Aquafarm: simulation and decision support for aquaculture facility design and management planning. Aquacultural Engineering 23, 121-179.

FAO, 2007. The State of World Fisheries and Aquaculture - 2006 (SOFIA). Food and agriculture organization of the United Nations, Rome, http://www.fao.org/fishery/, ISBN 978-92-5-105568-7.

Gebauer, R., Eggen, G., Hansen, E., Eikebrook, B., 1991. Oppdretts teknologi - vannkvalitet og vannbehandling i lukkede oppdrettsanlegg. Tapir Forlag, Trondheim University, Norway.

Grau, P., Sutton, P. M., Henze, M., Elmaleh, S., Grady, C. P., Gujer, W., 
Koller, J., 1982. Recommended notation for use in the description of biological wastewater treatment processes. Wat. Res. 16, 1501-1505.

Henze, M., Grady, C. P. L., Gujer, W., Marais, G., Matsuo, T., 1987. A general model for single-sludge wastewater treatment systems. Wat. Res. 21, 505515.

Henze, M., Gujer, W., Mino, T., van Loosdrecht, M., 2000. Activated sludge models ASM1, ASM2, ASM2D and ASM3. Scientific and technical report no. 9, IWA Publishing, London, GB.

Holben, W., Williams, P., Saarinen, M., Srkilahti, L., Apajalahti, J., 2002. Phylogenetic analysis of intestinal microflora indicates a novel mycoplasma phylote in farmed and wild salmon. Microbial Ecology 44, 175-185.

Ip, Y., Chew, S., Randall, D., 2001. Ammonia toxicity, tolerance, and excretion. Fish Physiology 20, 109-148.

Jamu, D. M., Piedrahita, R. H., 2002. An organic matter and nitrogen dynamics model for the ecological analysis of integrated aquaculture/agriculture systems. Environmental modelling and software 17, 571-592.

Jimenez-Montealegre, Verdegem, M. C. J., Dam, A., Verreth, J. A. J., 2002. Conceptualization and validation of a dynamic model for the simulation of nitrogen transformations and fluxes in fish ponds. Ecological modelling 147, $123-152$.

Kissel, J. C., McCarty, P., Street, R. L., 1984. Numerical simulation of mixed culture biofilm. J. Environ. Eng. 110 (2), 393-411.

Li, L., Yakupitiyage, A., 2003. A model for food nutrient dynamics of semiintensive pond fish culture. Aquacultural Engineering 27, 9-38.

Losordo, T. M., Hobbs, A. O., 2000. Using computer spreadsheets for water flow and biofilter sizing in recirculating aquaculture production systems. Aquacultural Engineering 23, 95-102.

Maciejowski, J. M., 1989. Multivariable feedback design. Addison-Wesley Publishing Company, Reading, MA.

Maurer, M., Fux, C., Lange, D., Siegrist, H., 1999. Modelling denitrification in a moving bed of porous carriers from a low-loaded wastewater treatment plant. Wat. Sci. Tech. 39 (7), 251-159.

Noble, A., Summerfelt, S., 1996. Diseases encountered in rainbow trout cultured in recirculating systems. Annual Review of Fish Diseases 6, 65-92.

Ødegaard, H., Gisvold, B., Strickland, J., 2000. The influence of carrier size and shape in the moving bed biofilm process. Wat. Sci. Tech. 41 (4-5), 383-391.

Piedrahita, R. H., 2003. Reducing the potential environmental impact of tank aquaculture effluents through intensification and recirculation. Aquaculture 226 (1-4), 35-44.

Riche, M., Haley, D., Oetker, M., Garbrecht, S., Garling, D., 2004. Effect of feeding frequency on gastric evacuation and the return of appetite in tilapia. Aquaculture 234, 657-673.

Royce, P., Thornhill, N., 1991. Estimation of dissolved carbon dioxide concen- 
trations in aerobic fermentation. AIChE J. 37 (11), 1680-1686.

Rusten, B., Hellström, B. G., Hellström, F., Sehested, O., Skjelfoss, E., Svendsen, B., 2000. Pilot testing and preliminary design of moving bed biofilm reactors for nitrigen removal at the frevar wastewater treatment plant. Wat. Sci. Tech. 41 (4-5), 13-20.

Serrano, R., Simal-Julian, A., Pitarch, E., Henandez, F., 2003. Biomagnification study on organochlorine compounds in marine aquaculture: The sea bass (dicentrarchus labrax) as a model. Environ. Sci. Technol. 37, 33753381.

Spaangard, B., Huber, I., Nielsen, J., Nielsen, T., Appel, K., Gram, L., 2000. The microflora of rainbow trout intestine: a comparison of traditional and molecular identification. Aquaculture 182, 1-15.

Storebakken, T., Kvien, I., Shearer, K., Grisdale-Helland, B., Helland, S., 1999. Estimation of gastrointestinal evacuation rate in atlantic salmon (salmo salar) using inert markers and collection of faeces by sieving: evacuation of diets with fish meal, soybean meal or bacterial meal. Aquaculture 172, 291-299.

Sveier, H., Wathne, E., Lied, E., 1999. Growth, feed and nutrient utilisation and gastrointestinal evacuation time in atlantic salmon (salmo salar 1.): the effect of dietary fish meal particle size and protein concentration. Aquaculture 180, 265-282.

Tal, Y., Watts, J., Schreier, S., Sowers, K., Schreier, H., 2003. Characterization of the microbial community and nitrogen transformation processes associated with moving bed bioreactors in a closed recirculated mariculture system. Aquaculture 215, 187-202.

Wik, T., May 1999. On modeling the dynamics of fixed biofilm reactors with focus on nitrifying trickling filters. Ph.D. thesis, Chalmers University of Technology, SE-412 96 Göteborg, Sweden, iSBN 91-7197-797-X, www.s2.chalmers.se/publications.

Wik, T., 2003. Trickling filters and biofilm reactor modelling. Reviews in environmental engineering and bio/technology. 2, 193-212.

Wik, T., Breitholtz, C., 1996. Steady-state solution of a two-species biofilm problem. Biotechnol. Bioeng. 50 (6), 675-686.

Wright, P., Land, M., 1998. Urea production and transport in teleost fishes. Comp. Biochem. Physiol. 119A (1), 47-54. 